\title{
Fresh and cultured mouse islets differ in their response to nutrient stimulation
}

\author{
Mai Morsi, Torben Schulze, Eike Früh, Dennis Brüning, Uwe Panten and Ingo Rustenbeck \\ Institute of Pharmacology, Toxicology and Clinical Pharmacy, Technische Universität Braunschweig, Braunschweig, Germany
}

Correspondence should be addressed to I Rustenbeck: i.rustenbeck@tu-bs.de

\begin{abstract}
Observing different kinetics of nutrient-induced insulin secretion in fresh and cultured islets under the same condition we compared parameters of stimulus secretion coupling in freshly isolated and 22-h-cultured NMRI mouse islets. Stimulation of fresh islets with $30 \mathrm{mM}$ glucose after perifusion without nutrient gave a continuously ascending secretion rate. In 22-h-cultured islets the same protocol produced a brisk first phase followed by a moderately elevated plateau, a pattern regarded to be typical for mouse islets. This was also the response of cultured islets to the nutrient secretagogue alpha-ketoisocaproic acid, whereas the secretion of fresh islets increased similarly fast but remained strongly elevated. The responses of fresh and cultured islets to purely depolarizing stimuli (tolbutamide or $\mathrm{KCl}$ ), however, were closely similar. Signs of apoptosis and necrosis were rare in both preparations. In cultured islets, the glucose-induced rise of the cytosolic $\mathrm{Ca}^{2+}$ concentration started from a lower value and was larger as was the increase of the ATP/ADP ratio. The prestimulatory level of mitochondrial reducing equivalents, expressed as the NAD(P)H/FAD fluorescence ratio, was lower in cultured islets, but increased more strongly than in fresh islets. When culture conditions were modified by replacing RPMI with Krebs-Ringer medium and FCS with BSA, the amount of released insulin varied widely, but the kinetics always showed a predominant first phase. In conclusion, the secretion kinetics of fresh mouse islets is more responsive to variations of nutrient stimulation than cultured islets. The more uniform kinetics of the latter may be caused by a different use of endogenous metabolites.
\end{abstract}
Key Words
- cytosolic calcium concentration
- glucose
- insulin secretion
- metabolic amplification
- mitochondria

\section{Introduction}

The endocrine pancreas responds to an increase in ambient glucose with a biphasic pattern of insulin release, represented by a short (5-10 min) first phase, followed by a long, sustained second phase release. This unique feature is best shown in response to a 'square wave' glucose stimulus, either in vivo or in vitro $(1,2)$. It is obvious that such a stimulation pattern is non-physiological, but the resulting biphasic response is the hallmark of the healthy, metabolically well-coupled endocrine pancreas. In type 2 diabetes or in models of this disease, it displays varying degrees of a diminished insulin response, usually described to be more prominent during the first phase, but also recognizable during the second phase $(3,4,5)$.

The mechanisms underlying the glucose-induced biphasic pattern of insulin secretion are still incompletely understood in spite of intensive research activities in the area. Heterogeneity within the insulin granule pool and/or heterogeneity of the signals in stimulussecretion coupling may both contribute $(6,7)$. Nutrient secretagogues (glucose and a limited number of aminoand keto acids) act via a bifurcating pathway. The oxidative phosphorylation induces the electrical activity https://ec.bioscientifica.com https://doi.org/10.1530/EC-20-0289 (c) 2020 The authors Published by Bioscientifica Ltd (2020) 9, 769-782 
by closure of the ATP-sensitive $\mathrm{K}^{+}$channels ( $\mathrm{K}_{\mathrm{ATP}}$ channels), additional signals from the mitochondrial metabolism act further downstream (8).

Since depolarization-induced $\mathrm{Ca}^{2+}$ influx is considered to represent the 'triggering' signal of nutrientstimulated insulin secretion it is often assumed that the first phase is exclusively determined by the opening of voltage-dependent $\mathrm{Ca}^{2+}$ channels leading to the fusion of membrane-docked granules (9). The second phase in contrast would then be formed by the additional signals, which are referred to as 'amplifying pathway' (8). However, the characteristics of both first phase and second phase secretion were markedly influenced by modulating the pre-stimulatory conditions so as to affect the amplifying pathway $(10,11)$.

The effect of the amplifying pathway on the level of insulin secretion can be demonstrated by increasing the concentration of a nutrient secretagogue when the beta cells are already depolarized, either by pharmacological $\mathrm{K}_{\text {ATP }}$ channel closure (12) or by $\mathrm{K}^{+}$depolarization plus pharmacological $\mathrm{K}_{\mathrm{ATP}}$ channel opening (13). When the $\mathrm{K}_{\mathrm{ATP}}$ channel closure takes place in the absence of exogenous nutrient, the metabolic amplification by a subsequent glucose stimulation is lost; however, the metabolic amplification by the keto acid alpha-ketoisocaproic acid (KIC) remains intact (14). This discrepancy between the amplifying effect of two nutrient secretagogues may lead to the unambiguous identification of the relevant signaling metabolites in this pathway, which has not yet been achieved $(15,16)$.

Investigating the mechanisms leading to the glucoseselective loss of the metabolic amplification, we observed that a marked difference existed between the response of freshly isolated islets and that of cultured islets. So we tested the hypothesis that the cell culture phase, which is often routinely employed after collagenase digestion of the islets (17) does not just re-establish pre-isolation conditions, but leaves its mark on the metabolic signaling in the beta cells and, in consequence, the kinetics of nutrient-induced insulin secretion.

\section{Materials and methods}

\section{Chemicals}

Collagenase for islet isolation was initially NB8 from Serva (Heidelberg, Germany), in later experiments collagenase P from Roche (Sigma) was used. Fura-2 LeakRes (AM) was obtained from TEF-Labs (Austin, TX, USA). Cell culture medium RPMI 1640 without glucose was from Sigma and fetal calf serum (FCS Gold ADD) was from Bio \& Sell (Nürnberg-Feucht, Germany). BSA (fraction V) and all other reagents of analytical grade were from E. Merck.

\section{Tissue and tissue culture}

Islets were isolated from the pancreas of female NMRI mice (12-16 weeks old, fed ad libitum) by a collagenase digestion technique and hand-picked under a stereomicroscope (for details see (18)). For some of the experiments the islets were microdissected to avoid contact with the collagenase. Care was taken to limit the time between onset of digestion and start of the perifusion of freshly isolated islets to $45 \mathrm{~min}$. For a direct comparison between freshly isolated islets and cultured islets the same batch of islets was split in two. Islets were cultured in cell culture medium RPMI 1640 and 10\% fetal calf serum ( $\mathrm{vol} / \mathrm{vol})$ in a humidified atmosphere of $95 \%$ air and $5 \%$ $\mathrm{CO}_{2}$ at $37^{\circ} \mathrm{C}$. In some of the experiments FCS was replaced by $0.4 \%(\mathrm{w} / \mathrm{v})$ BSA since this concentration comes close to the protein concentration of a medium with $10 \%$ FCS supplementation. The glucose concentration during culture was set at $5 \mathrm{mM}$ (by adding glucose to glucosefree RPMI), except when specifically stated otherwise. The culture duration was always $22 \mathrm{~h}$. Animal care was supervised by the regional authority (LAVES, Lower Saxony, Germany) and conformed to the current EU regulations.

\section{Integrity of freshly isolated and cultured islets}

The appearance of freshly isolated islets and cultured islets was checked using transmitted light microscopy with DICcontrast. Islets were placed in an open chamber with glass bottom and a water immersion objective (Zeiss Achroplan $40 \times, 0.75$ w) was used for inspection. Photomicrographs were taken by a Panasonic Lumix GX80 at the photo port of the upright Zeiss Axioscope FS microscope. The relation of live and dead cells in the islets was assessed by the live/dead assay according to the manufacturer's protocol (PromoCell, Heidelberg, Germany). The non-fluorescent membrane-permeable Calcein AM-ester is cleaved in the cytosol of living cells whereby a green fluorescence is produced and retained within the cell when the plasma membrane is intact. Ethidium homodimer III is excluded from a living cell with an intact plasma membrane but can reach the nucleus of dead cells. There it binds to nuclear DNA whereby the red fluorescence is about 40-fold intensified. The occurrence of early steps of apoptosis in fresh and cultured islets was checked by annexin $\mathrm{V}$ 
assay (ABP Biosciences, Rockwell, MD, USA). Andy Fluor 488-coupled annexin $\mathrm{V}$ binds to the outer leaflet of the plasma membrane if phosphatidylserine is present, which indicates the onset of apoptosis (19). The number of dead cells is again indicated by the red fluorescence of ethidium homodimer III. After loading with the indicators, islets were placed on Petri dishes with glass bottom (ibidi GmbH, Gräfelfing, Germany) and placed on the stage of an inverted Nikon Ti2-E microscope fitted with a Yokogawa CSU W1 spinning disk unit. The green fluorescence of calcein and of Alexa Fluor 488 was excited at $491 \mathrm{~nm}$, the red fluorescence of ethidium homodimer at $561 \mathrm{~nm}$ and collected by a Nikon CFI Plan Apochromat Lambda S40 XC Sil objective (40×, 1.25 N.A.), which is designed to image thick specimen of living cells. Images were acquired by a sCMOS camera (Prime BSI, Teledyne Photometrics, Tucson, AZ, USA) under control of Visiview Premier software (Visitron Systems, Munich, Germany).

\section{Measurement of insulin secretion and insulin content}

Batches of 50 islets were introduced into a purpose-made perifusion chamber $\left(37^{\circ} \mathrm{C}\right)$ and perifused at $0.9 \mathrm{~mL} / \mathrm{min}$ with a HEPES-buffered KR medium $(\mathrm{NaCl} 118.5 \mathrm{mM}$, $\mathrm{KCl} 4.7 \mathrm{mM}, \mathrm{CaCl}_{2} 2.5 \mathrm{mM}, \mathrm{KH}_{2} \mathrm{PO}_{4} 1.2 \mathrm{mM}, \mathrm{MgSO}_{4}$ $1.2 \mathrm{mM}, \mathrm{NaHCO}_{3} 20 \mathrm{mM}$, HEPES $10 \mathrm{mM}$, BSA $0.2 \%$, w/v) which was saturated with $95 \% \mathrm{O}_{2}$ and $5 \% \mathrm{CO}_{2}$ and contained the respective secretagogue. This medium was also used for the microfluorometric measurements. The insulin content in the fractionated efflux was determined by ELISA according to the manufacturer's protocol (Mercodia, Uppsala, Sweden). The islet insulin content was measured by sonicating a group of 30 islets in an ice-cooled microtube for $20 \mathrm{~s}$ and measuring the insulin concentration after appropriate dilution with the zero buffer of the ELISA set.

\section{Measurement of islet $\mathrm{NAD}(\mathrm{P}) \mathrm{H}$ - and FAD-autofluorescence}

The islet autofluorescence of NAD(P)H $(\mathrm{NADH}+\mathrm{NADPH})$ and of $\operatorname{FAD}(20,21)$ was simultaneously recorded. One islet was perifused in a purpose-made chamber on the stage of an Orthoplan epifluorescence microscope (Leitz/Leica) with KR-medium at $0.2 \mathrm{~mL} / \mathrm{min}$ and $35^{\circ} \mathrm{C}$. After selecting a subregion of the islet fluorescence was excited with a 150W xenon arc using the following filter combinations (Omega Optical, Brattleboro, VT, USA): for $\mathrm{NAD}(\mathrm{P}) \mathrm{H}$, excitation $366 \pm 15 \mathrm{~nm}$ bandpass, dichroic separation
$405 \mathrm{~nm}$, emission $450 \pm 32 \mathrm{~nm}$ bandpass; for FAD, excitation $440 \pm 21 \mathrm{~nm}$ bandpass, dichroic separation $455 \mathrm{~nm}$, emission $520 \pm 20 \mathrm{~nm}$ bandpass. The filter cubes were switched every $2.5 \mathrm{~s}$ with an exposure time of $0.1 \mathrm{~s}$. The fluorescence was collected by a Zeiss Fluar (10×, 0.5 N.A.) and quantified by a photon-counting multiplier. To calculate mean values, the fluorescence intensities were normalized to $100 \%$ at the last prestimulatory time point in each single experiment. Since

\section{Simultaneous measurement of the cytosolic $\mathrm{Ca}^{2+}$ concentration $\left(\left[\mathrm{Ca}^{2+}\right]_{\mathrm{i}}\right)$ and insulin secretion}

Freshly isolated or cultured islets were incubated in KR medium (5 mM glucose) with Fura-2 LeakRes (AM) at a concentration of $2 \mu \mathrm{M}$ for $45 \mathrm{~min}$ at $37^{\circ} \mathrm{C}$. Five islets were then inserted in a temperature-controlled perifusion chamber $\left(35^{\circ} \mathrm{C}\right)$ on the stage of a Zeiss Axiovert 135 microscope equipped with a Zeiss Fluar (10×, 0.5 N.A.) objective and perifused with KR-medium. The fluorescence of each islet (excitation at 340 or $380 \mathrm{~nm}$, dichroic separation at $400 \mathrm{~nm}$, emission $510 \pm 40 \mathrm{~nm}$ bandpass) was recorded with a cooled CCD camera (Pursuit, Diagnostics Instruments, Sterling Heights, MI, USA) and evaluated using Visiview software (Visitron, Munich, Germany). The insulin content of the fractionated efflux was determined by ELISA (Mercodia, Uppsala, Sweden).

\section{Islet content of adenine nucleotides}

Fifteen cultured or fresh islets were statically incubated to mimic typical perifusion conditions. Thereafter, proteins were precipitated and the adenine nucleotides were extracted as described (14). ATP was determined by use of the luciferase method. The ADP content of the extract was converted into ATP by the pyruvate kinase reaction, the difference between both measurements yielding the net ADP content. Because of the interindividual variations in the adenine nucleotide contents the incubations were strictly performed in parallel and comparison between cultured and fresh islets was only made with islets from the same isolation batch.

\section{Statistics}

Results are presented as mean \pm s.E.M. GraphPad Prism5 software (GraphPad) was used for statistic calculations and non-linear curve fitting (ELISA). If not specified otherwise, 'significant' refers to $P<0.05$, unpaired, two-sided $t$-test.

This work is licensed under a Creative Commons Attribution-NonCommercial-NoDerivatives 4.0 Internationab ficense.ifica com at 04/26/2023 04:26:16AM 


\section{Results}

\section{Cultured and fresh islets respond differently to the same stimulation}

As shown previously (14) $30 \mathrm{mM}$ glucose induced a modest first and pronounced second phase insulin secretion from freshly isolated islets after $60 \mathrm{~min}$ absence of exogenous nutrients (Fig. 1A) and was even unable to stimulate secretion when the islets were depolarized by tolbutamide during the initial nutrient deficiency (Fig. 1B). These initial experimental conditions had much less effect on KIC-stimulated insulin secretion, which was pronounced irrespective of whether or not the initial period of nutrient deficiency was combined with tolbutamide (Fig. $1 \mathrm{C}$ and D). We now unexpectedly observed that the loss of glucose-stimulated secretion did not occur when the initial nutrient deficiency in the presence of tolbutamide was preceded by 22 -h islet culture (Fig. 1B). Islet culture also changed the kinetics of glucose- and KIC-induced secretion after nutrient deficiency. In both cases (Fig. 1A and $\mathrm{C}$ ) the secretory response switched from dominating second phase to dominating first phase secretion. Only in the case of KIC-stimulation after preceding depolarization in the absence of exogenous nutrient the secretion pattern was qualitatively similar to that of freshly isolated islets (Fig. 1D).

\section{Similar kinetics of $\left[\mathrm{Ca}^{2+}\right]_{i}$ but not of insulin secretion during glucose stimulation in cultured and fresh islets}

To assess the role of the cytosolic $\mathrm{Ca}^{2+}$ concentration $\left(\left[\mathrm{Ca}^{2+}\right]_{\mathrm{i}}\right)$ and to verify the different responses of fresh and cultured islets, $\left[\mathrm{Ca}^{2+}\right]_{\mathrm{i}}$ in perifused islets was measured simultaneously with the insulin secretion (Fig. 2). Elevating glucose from 0 to $30 \mathrm{mM}$ produced a peak of secretion of cultured islets during the first $10 \mathrm{~min}$, concurrent with a steep increase of $\left[\mathrm{Ca}^{2+}\right]_{\mathrm{i}}$, which was preceded by a modest transient decrease of both $\left[\mathrm{Ca}^{2+}\right]_{\mathrm{i}}$ and secretion (Fig. 2A). The tolbutamide-induced depolarization in the absence of nutrient was clearly effective to sustain elevated $\left[\mathrm{Ca}^{2+}\right]_{\mathrm{i}}$ levels. Under this condition $30 \mathrm{mM}$ glucose initially caused a deep decrease of $\left[\mathrm{Ca}^{2+}\right]_{i}$ before eliciting a steep increase. The peak of secretion had the same height and occurred at the same time as under control condition (Fig. 2B).

With freshly isolated islets $30 \mathrm{mM}$ glucose led to a response with a moderate first phase and a continuously
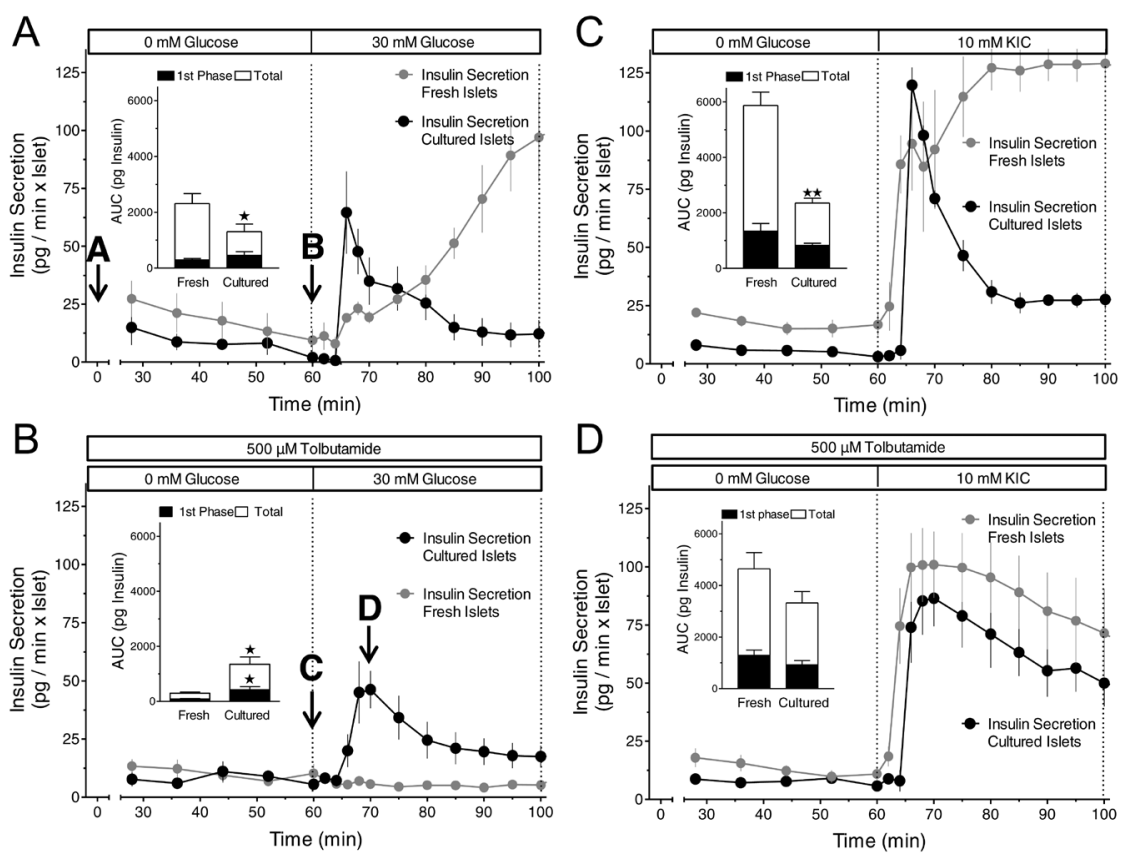

\section{Figure 1}

Predominance of the first phase response in cultured mouse islets (black symbols) as compared to the variable response pattern in freshly isolated mouse islets (grey symbols). (A) 22-h-cultured islets were perifused with KrebsRinger medium containing $0 \mathrm{mM}$ glucose for 60 min, then $30 \mathrm{mM}$ glucose was present for $40 \mathrm{~min}$. The increase of the glucose concentration from 0 to $30 \mathrm{mM}$ glucose elicited virtually opposite kinetics of secretion in fresh and in cultured islets. (B) Same protocol as in A with $500 \mu \mathrm{M}$ tolbutamide additionally present throughout the perifusion. Note a virtually complete loss of glucose stimulation with fresh islets but not with cultured islets. (C) Same protocol as in A except for using $10 \mathrm{mM} \mathrm{KIC} \mathrm{instead} \mathrm{of} 30 \mathrm{mM}$ glucose as the nutrient secretagogue. The KIC-induced high level of secretion was only maintained in fresh islets. (D) Same protocol as in B except for using $10 \mathrm{mM} \mathrm{KIC}$ instead of $30 \mathrm{mM}$ glucose as the nutrient secretagogue. Note the robust response of fresh islets to KIC stimulation as compared to the loss of glucose stimulation in B. Values are means \pm S.E.M. of $4-5$ experiments each. The inset shows the integrated insulin secretion from 60 to $75 \mathrm{~min}$ (first phase) and from 60 to $100 \mathrm{~min}$ (total). $* P<0.05, * * P<0.01$, cultured vs fresh islets under the same condition, unpaired two-sided $t$-test. The secretion data obtained with fresh islets are taken from Schulze et al. (16). https://ec.bioscientifica.com https://doi.org/10.1530/EC-20-0289 (c) 2020 The authors Published by Bioscientifica Ltd
This work is licensed under a Creative Commons Attribution-NonCommercial-NoDerivatives 4.0 internationab dicense.ifica.com at $04 / 26 / 2023$ 04:26:16AM 

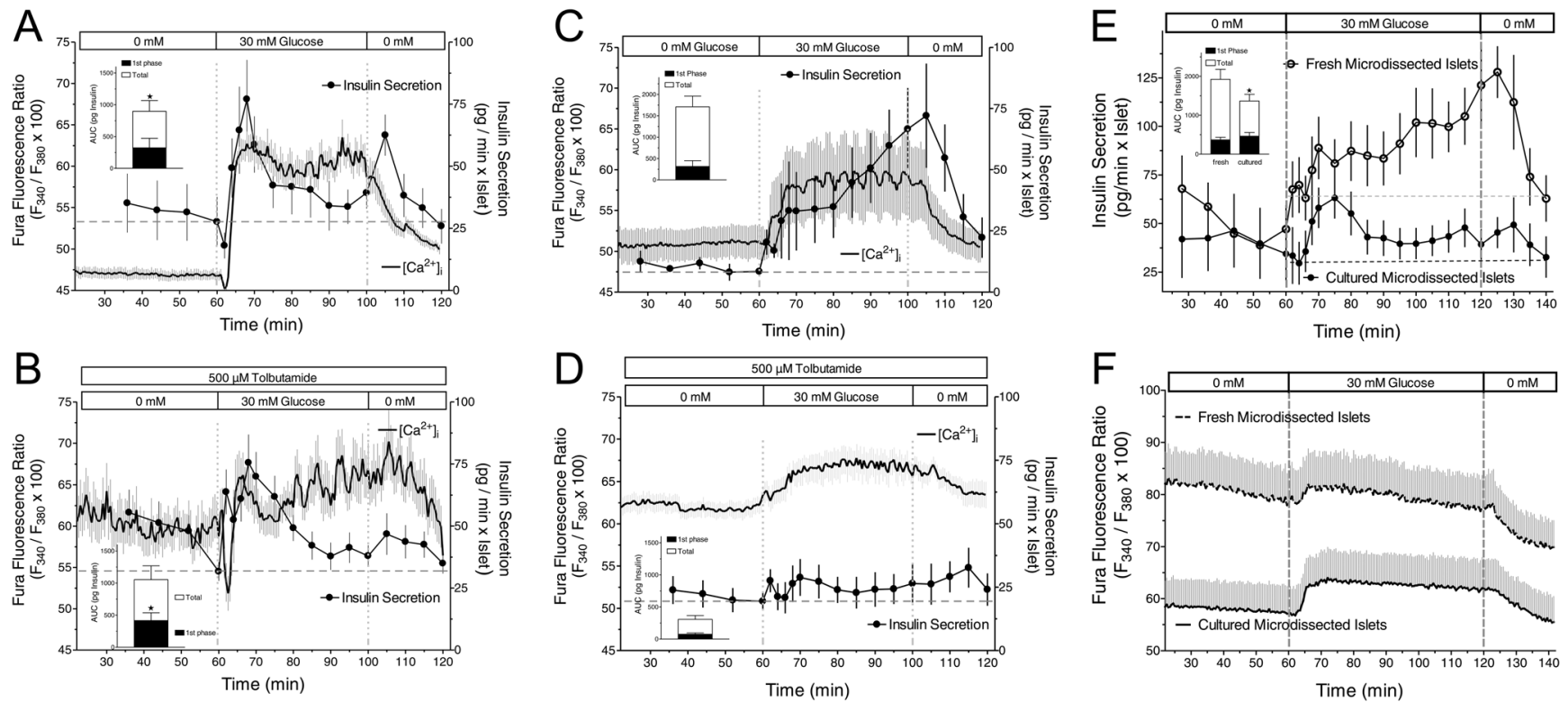

Figure 2

Simultaneous measurement of the cytosolic $\mathrm{Ca}^{2+}$ concentration and insulin secretion by cultured (A and B) or freshly isolated islets (C and D) in response to glucose. Fura-2-loaded islets were perifused with Krebs-Ringer medium containing 0 mM glucose (A and C) or 0 mM glucose plus $500 \mu \mathrm{M}$ tolbutamide $(B$ and $D$ ) for $60 \mathrm{~min}$, then glucose was raised to $30 \mathrm{mM}$ for $40 \mathrm{~min}$ and washed out thereafter. The Fura fluorescence ratio of three to five islets was measured per experiment, the secretion was measured in the fractionated efflux of these islets. Upon glucose stimulation the cultured islets show a plateau-like second phase after a predominant first phase. Freshly isolated islets show an ascending second phase (C) or a virtual loss of the insulinotropic effect of glucose (D). The difference in the secretion kinetics of the second phase is not paralleled by different kinetics of the Fura ratio value (compare A and C). Values are means \pm S.E.M. of 4-7 experiments. The experiments shown in A and C were repeated with microdissected islets ( $E$ and F). Note again the different kinetics of the second phase secretion (E) in cultured (closed circles) as compared with freshly isolated islets (open circles), which is not reflected by the respective Fura ratio values (F). Values are means \pm S.E.M. of seven experiments each. The inset shows the integrated insulin secretion from 60 to 75 min (first phase) and from 60 min to washout (total). *P<0.05, cultured vs fresh islets under the same condition, unpaired two-sided $t$-test.

ascending second phase (Fig. 2C). The prestimulatory $\left[\mathrm{Ca}^{2+}\right]_{\mathrm{i}}$ level was higher than in cultured islets, and the increase by glucose was less steep but reached a similar extent (compare Fig. 2A and C). In fresh islets the tolbutamide-induced depolarization in the absence of nutrient led to a strong inhibition of the secretory response to subsequent glucose stimulation (Fig. 2D). Tolbutamide led to prestimulatory $\left[\mathrm{Ca}^{2+}\right]_{\mathrm{i}}$ levels which were similar as those in cultured islets (compare Fig. 2B and D). While the $\left[\mathrm{Ca}^{2+}\right]_{\mathrm{i}}$ increase in response to $30 \mathrm{mM}$ glucose was slow the levels attained were not less than under control condition.

To check for a specific role of collagenase-induced defects in shaping the secretion pattern of freshly isolated islets the effect of glucose on microdissected and cultured microdissected islets was compared (Fig. 2E and F). In response to $30 \mathrm{mM}$ glucose fresh microdissected islets showed a continuously ascending second phase, whereas cultured islets from the same batch showed a predominant first phase followed by a moderately elevated plateau (Fig. $2 E)$. Again the $\left[\mathrm{Ca}^{2+}\right]_{i}$ values in fresh islets were higher than in cultured islets, but both were higher than those of the corresponding collagenase-isolated islets (Fig. 2F, compare with Fig. 2A and C). This was likely caused by damaged residual exocrine cells still attached to the islets (Supplementary Fig. 1, see section on supplementary materials given at the end of this article). Upon glucose stimulation, the $\left[\mathrm{Ca}^{2+}\right]_{\mathrm{i}}$ pattern of fresh and cultured islets was qualitatively similar (Fig. 2F), in marked contrast with the secretion kinetics.

\section{Similar metabolic and structural integrity of cultured and fresh islets}

The generally higher prestimulatory $\left[\mathrm{Ca}^{2+}\right]_{\mathrm{i}}$ levels in fresh islets gave rise to the concern that the secretion kinetics of these islets resulted from beta cell damage and that the more pronounced first phase was an expression of recovery by overnight culture. Therefore the viability of fresh and cultured islets was compared using the live/dead assay and imaging by spinning disk confocal microscopy. With both preparations the entirety of the islet was labelled by 
A

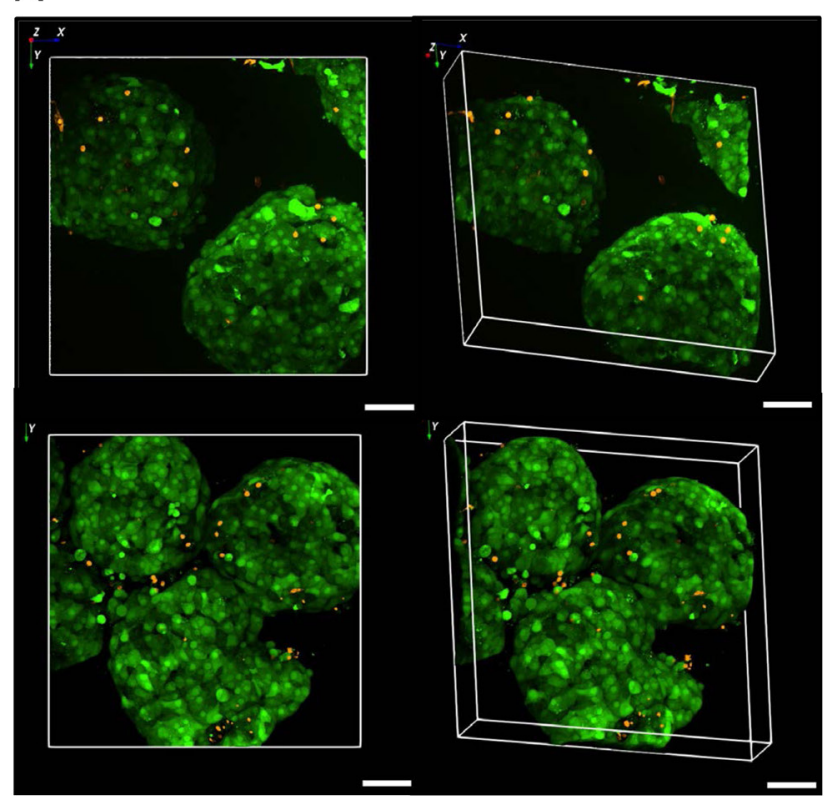

C

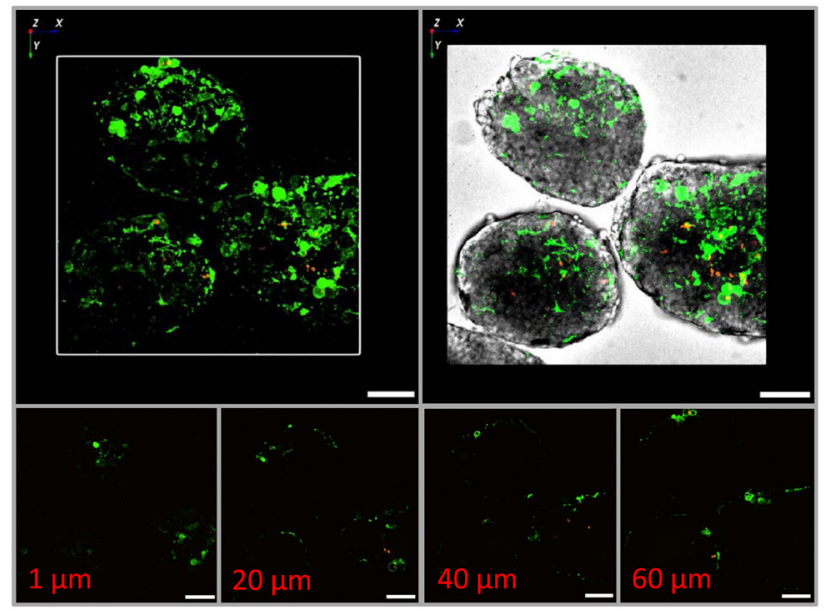

B

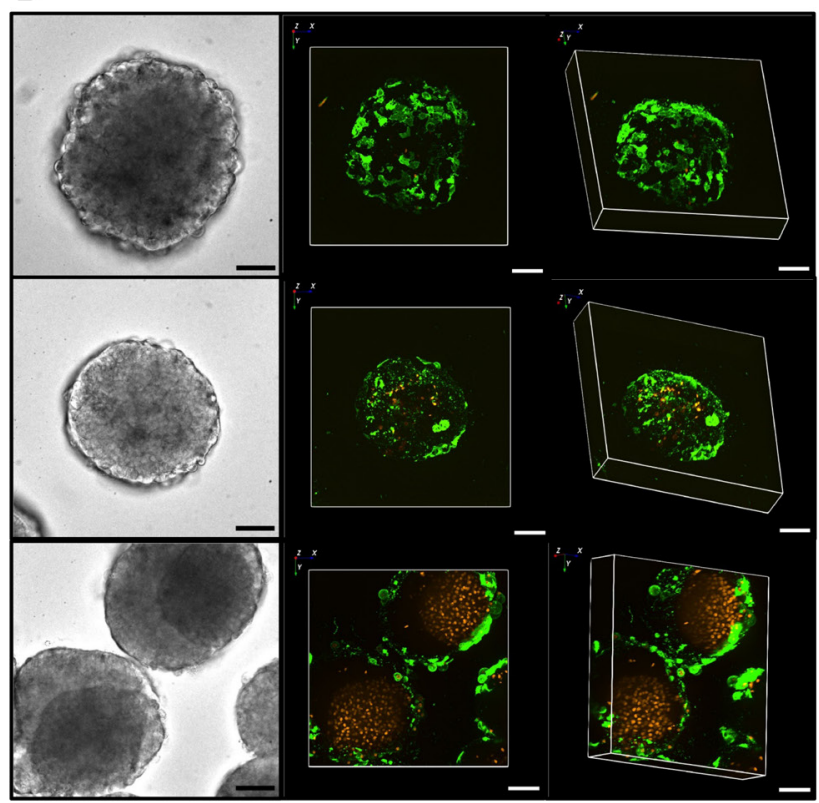

D

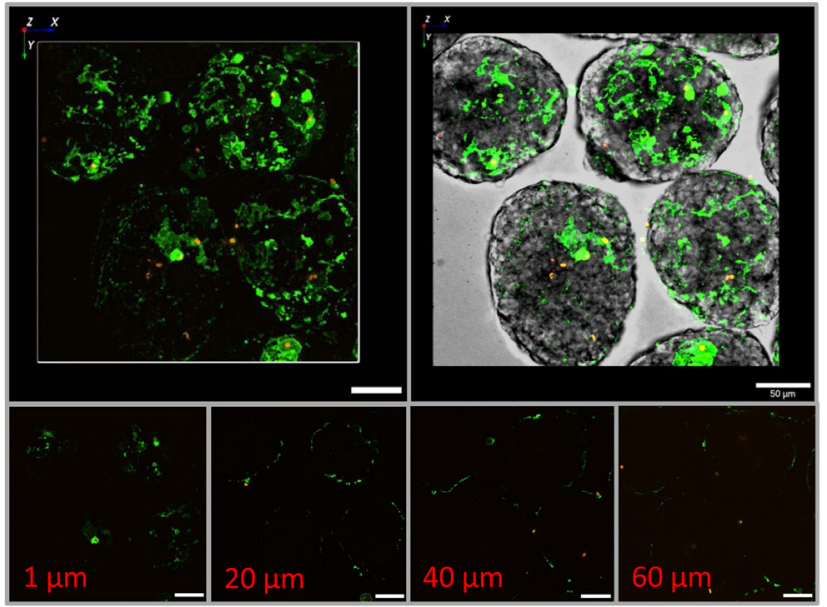

Figure 3

Visualization of intact, apoptotic and necrotic cells in freshly isolated or cultured islets. (A) Freshly isolated (upper row) or 22-h-cultured (lower row) islets were loaded with calcein/AM and ethidium homodimer III. The red ethidium fluorescence of necrotic nuclei is occasionaly visible in the islet periphery, whereas the green fluorescence of the viability indicator calcein renders the entirety of the fresh and cultured islets visible. Representative images of five experiments. (B) Freshly isolated (upper row) or 22-h-cultured (middle row) islets were loaded with annexinV-Andy Fluor 488 to indicate incipient apoptosis and ethidium homodimer III to indicate necrotic nuclei. Beginning apoptosis is only visible in the outermost cell layer of fresh and cultured islets. Necrosis is negligible when compared to cultured islets showing a condensed core in transmitted light (lower row). Representative images of five experiments. (C and D) Fresh islets loaded with annexinV-Andy Fluor 488 and ethidium homodimer III were incubated for 60 min in Krebs-Ringer medium with $5 \mathrm{mM}$ glucose (C) or $0 \mathrm{mM}$ glucose (D); Shown is the epifluorescence (upper left) and the epifluorescence projected on the transmitted light image of the islets (upper right). Optical sections of the islets were made at depths of $1 \mu \mathrm{m}$ (lower left), $20 \mu \mathrm{m}$ (lower left middle), $40 \mu \mathrm{m}$ (lower right middle) and $60 \mu \mathrm{m}$ (lower right). Representative images of three experiments each.

the calcein fluorescence, indicating that these cells had an intact plasma membrane. With both preparations fluorescent red dots, which indicate necrotic cells, were rare and confined to the islet periphery (Fig. 3A).

Since the live/dead assay gives only a rather coarse view on the islet integrity and may not report on incipient damage, the possible onset of apoptosis was checked by the binding of fluorescently labelled annexin V (Fig. 3B). The binding of annexin $\mathrm{V}$ was confined to outermost cell layer of the fresh islets, in the same region red dots of ethidium binding were occasionally visible. The same pattern was seen with islets that had spent $22 \mathrm{~h}$ in culture https://ec.bioscientifica.com https://doi.org/10.1530/EC-20-0289 (c) 2020 The authors Published by Bioscientifica Ltd

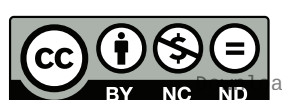

This work is licensed under a Creative Commons Attribution-NonCommercial-NoDerivatives 4.0 International License.ifica com at $04 / 26 / 2023 \quad 04: 26: 16 \mathrm{AM}$ 

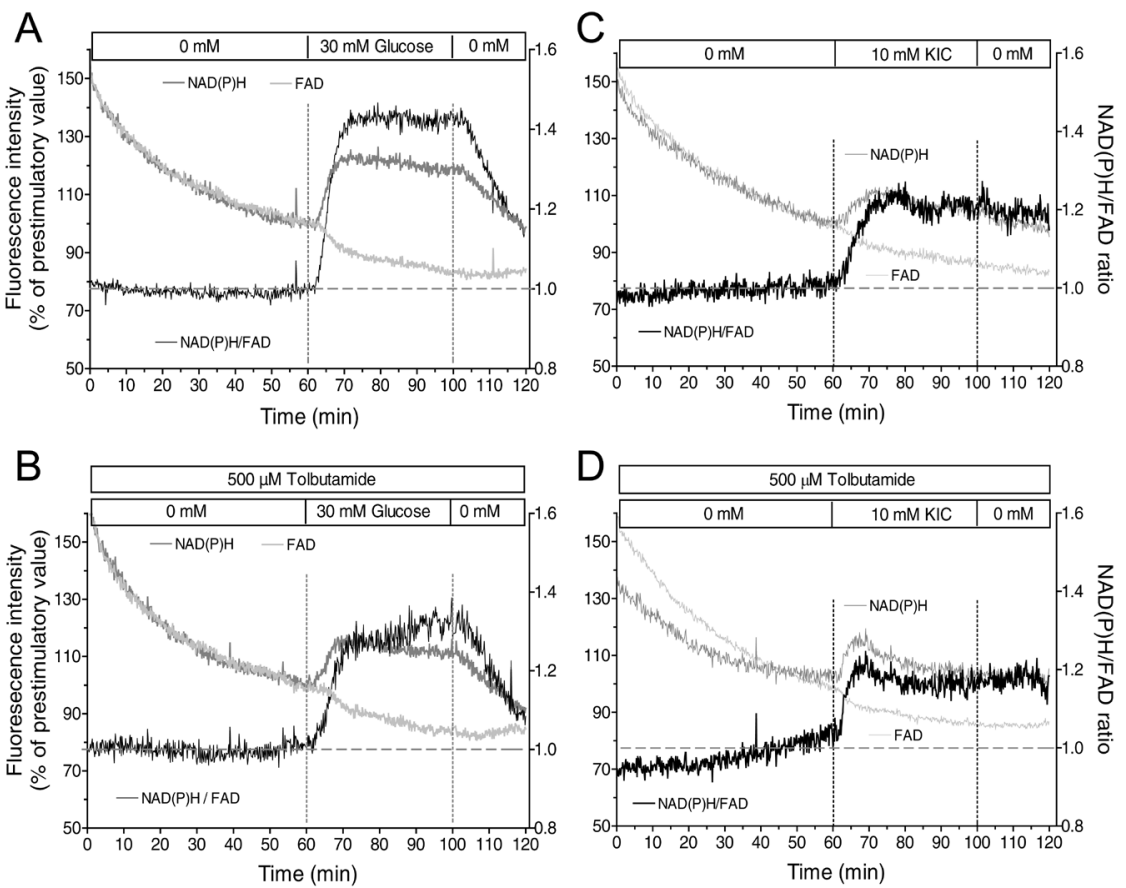

\section{Figure 4}

Increased levels of reducing equivalents by stimulation with nutrient secretagogues.

22-h-cultured isolated islets were perifused with Krebs-Ringer medium in the absence ( $A$ and $C$ ) or presence ( $B$ and $D$ ) of $500 \mu \mathrm{M}$ tolbutamide. After perifusion without exogenous nutrient for $60 \mathrm{~min}$ either $30 \mathrm{mM}$ glucose (A and B) or $10 \mathrm{mM} \mathrm{KIC}$ (C and D) was present from 60 to $100 \mathrm{~min}$. From 100 to 120 min the nutrient stimuli were washed out. The fluorescence intensities were normalized to $100 \%$ at the last prestimulatory time point. The dark gray traces denote the $\mathrm{NAD}(\mathrm{P}) \mathrm{H}$ autofluorescence, the light gray traces the FAD autofluorescence and the black traces the $\mathrm{NAD}(\mathrm{P}) \mathrm{H} / \mathrm{FAD}$ ratio as a semi-quantitative measure of mitochondrial reducing equivalents. Note the smaller and less reversible changes of the autofluorescences by KIC as compared with glucose. Values are means of 4-6 experiments each. S.E.M. ranges are omitted for clarity. under the same conditions as for functional testing. Islets which showed a dense core in transmitted light after culture were imaged as positive controls. While a thin mantle of annexin V-positive cells was also visible here, a massive accumulation of red fluorescent nuclei in the islet core demonstrated the extent of necrosis. Such extent of necrosis was never seen among the freshly isolated islets.

Finally, to test for the potentially damaging effect of the absence of nutrient in the perifusion medium for $1 \mathrm{~h}$, the annexin $\mathrm{V}$ labeling was used to compare islets which had spent $1 \mathrm{~h}$ in the presence of $5 \mathrm{mM}$ glucose with those which had spent the same time in the absence of glucose (Fig. 3C and D). A sketchy labeling in the outermost cell layer was visible after either treatment, but the islet core (which should be most sensitive to starvation) was practically unaffected.

\section{Kinetics of nutrient-generated reducing equivalents in cultured islets}

Since both triggering and amplifying signals emanate from the mitochondrial metabolism, the stimulation-induced changes of the NAD(P)H- and FAD-autofluorescence were measured under the same conditions as for the secretion measurements. The response to $30 \mathrm{mM}$ glucose consisted in an increase of the $\mathrm{NAD}(\mathrm{P}) \mathrm{H}$ - and a slightly retarded decrease of the FAD-autofluorescence, both of which were promptly reversible upon washout. The specific increase in the levels of reducing equivalents can be highlighted by calculating the NAD(P)H/FAD ratio (Fig. 4A). The ratio showed a steady state followed by a steep increase during the first $10 \mathrm{~min}$ of glucose stimulation. Thereafter, an elevated plateau existed which decreased by 50\% within 15 min upon wash-out. After tolbutamide-depolarization in the absence of exogenous nutrient glucose still elicited a qualitatively similar response, however the increase of the $\mathrm{NAD}(\mathrm{P}) \mathrm{H} / \mathrm{FAD}$ ratio was smaller by about 30\% (Fig. $4 \mathrm{~B})$. KIC produced an increase of the NAD(P)H/FAD-ratio which was smaller than the one by glucose by about $50 \%$ but which was practically unaffected by depolarization in the absence of nutrient (Fig. 4C and D). The kinetics of the $\mathrm{KIC}$ response was different from glucose in that an initial overshoot was followed by a moderately elevated plateau, which did not decrease during the wash-out phase.

\section{Kinetics of nutrient-generated reducing equivalents in cultured islets in comparison with those in fresh islets}

Since the NAD $(\mathrm{P}) \mathrm{H}$ - and FAD- fluorescence measurements were normalized to $100 \%$ with respect to the last prestimulatory value, a direct comparison with the normalized data of the earlier $\mathrm{NAD}(\mathrm{P}) \mathrm{H}$ - and FADmeasurements of fresh islets (16) could be misleading (Supplementary Fig. 2). Actually, the prestimulatory levels of the $\mathrm{NAD}(\mathrm{P}) \mathrm{H}$ - as well as the FAD-autofluorescence were two- to threefold lower in cultured islets than in fresh islets (Fig. 5A and Supplementary Fig. 3). Furthermore, 

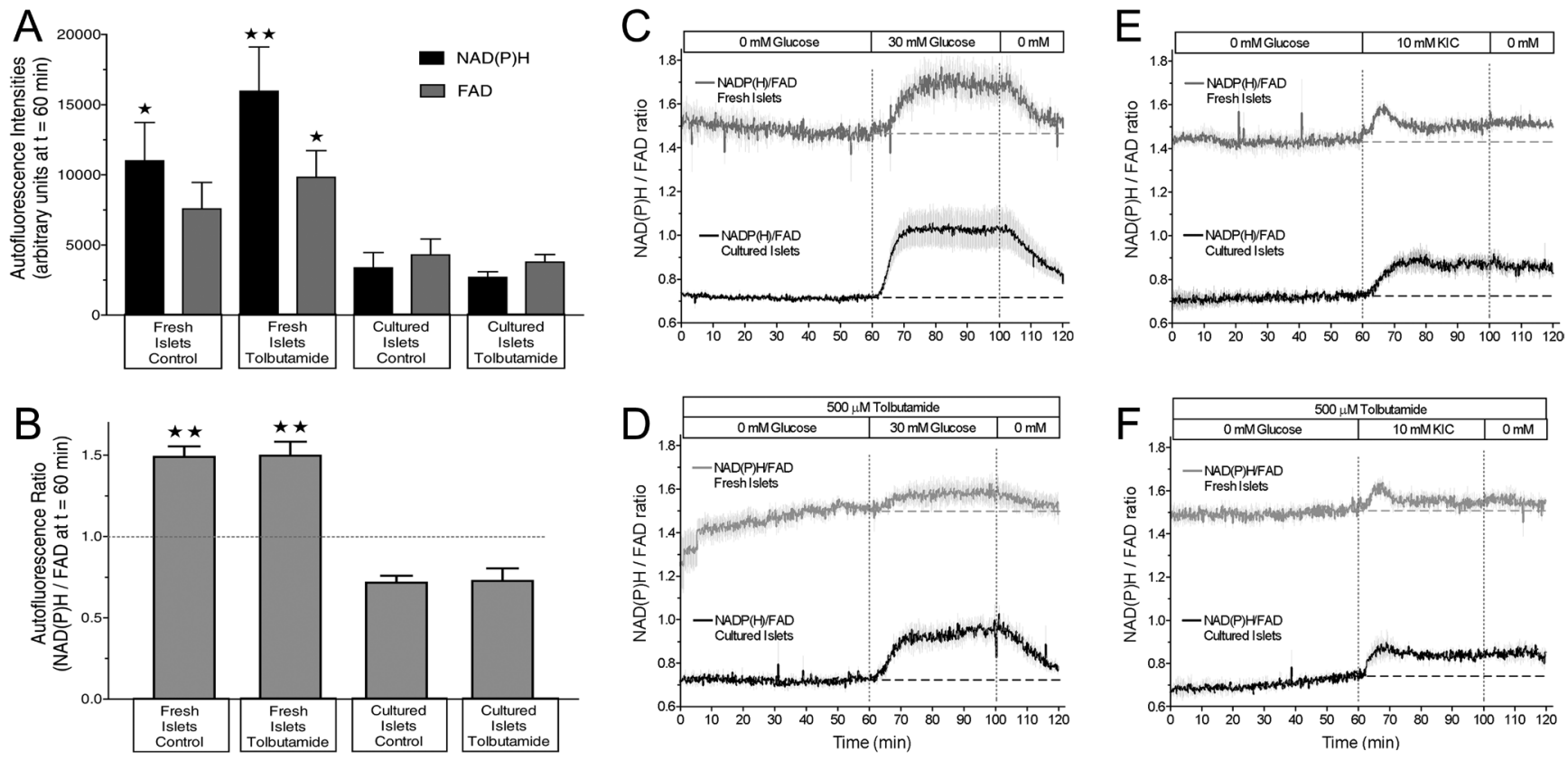

\section{Figure 5}

Nutrient-induced increase of reducing equivalents in cultured islets as compared with freshly isolated islets. (A) Immediately prior to nutrient stimulation the $\mathrm{NAD}(\mathrm{P}) \mathrm{H}$ - and FAD-autofluorescence levels in cultured islets were significantly lower than in fresh islets (values taken from Schulze et al. 16). (B) At the same time point the $N A D(P) H / F A D$ ratio in cultured islets was significantly lower than in fresh islets. Values are means of 4-6 experiments each. ${ }^{*} P<0.05$, $\star \star P<0.01$ cultured vs fresh islets under the same condition. (C-F) These values were taken to enable an unbiased comparison of the NAD(P)H/FAD ratio kinetics of cultured islets (shown in Fig. 4) with those of freshly isolated islets. After perifusion without exogenous nutrient for $60 \mathrm{~min}$ either $30 \mathrm{mM}$ glucose ( $C$ and D) or $10 \mathrm{mM} \mathrm{KIC} \mathrm{(E} \mathrm{and} \mathrm{F)} \mathrm{was} \mathrm{present} \mathrm{from} 60$ to $100 \mathrm{~min}$. In D and F $500 \mu \mathrm{M}$ tolbutamide was continuously present. Values are means \pm S.E.M. of 4-6 experiments each.

the $\mathrm{NAD}(\mathrm{P}) \mathrm{H}$-levels in cultured islets were more diminished than the FAD-levels, thus the prestimulatory NAD(P)H/FAD ratio in cultured islets was only about half as high as the one in fresh islets ( 0.75 vs 1.5 see Fig. $5 \mathrm{~B}$ ). These factors were used to make the NAD(P)H/FAD-ratios of cultured and fresh islets directly comparable (Fig. 5C, $\mathrm{D}, \mathrm{E}$ and F). While the overall response pattern to nutrient stimulation was similar, for example, the response to glucose differed from that to KIC by the same criteria, the ratio values were constantly lower in the cultured islets. The most pronounced difference between cultured and fresh islets was visible when the glucose stimulus was applied in the presence of tolbutamide (Fig. 5D), which fits to the difference in secretion (Fig. 1B).

\section{Different reactions of adenine nucleotide levels in cultured and fresh islets}

The contents of ATP and ADP of 22-h-cultured islets and freshly isolated islets were determined after static incubations designed to reflect four critical time points of the perifusion experiments: First, without incubation (Fig. 6A); second, $60 \mathrm{~min}$ in the absence of glucose or any other exogenous nutrient (Fig. 6B); third, 60 min without nutrient but with the additional presence of $500 \mu \mathrm{M}$ tolbutamide (Fig. 6C); and finally (6D) $60 \mathrm{~min}$ as before plus $10 \mathrm{~min}$ exposure to $30 \mathrm{mM}$ glucose in the continued presence of tolbutamide (see also the labels A-D in Fig. 1A and B). Without incubation neither ATP nor ADP nor the ATP/ADP ratio were significantly different, whereas after $60 \mathrm{~min}$ in the absence of exogenous nutrient all three parameters where higher in fresh islets. When tolbutamide was additionally present only ATP and ADP, but not the ATP/ADP ratio were higher in fresh islets. In this situation, the stimulation by glucose led to significantly higher levels of the ATP/ADP ratio in cultured islets, mainly due to lower levels of ADP. In short, the levels of adenine nucleotides are similar in cultured and fresh islets, but they evolve differently in response to nutrient deprivation and stimulation.

\section{Minor difference between cultured and fresh islets in responding to purely depolarizing stimuli}

To examine whether cultured and fresh islets respond differently to purely depolarizing stimuli the
This work is licensed under a Creative Commons Attribution-NonCommercial-NoDerivatives 4.0 elnternational License.ifica com at $04 / 26 / 2023 \quad 04: 26: 16 \mathrm{AM}$ 


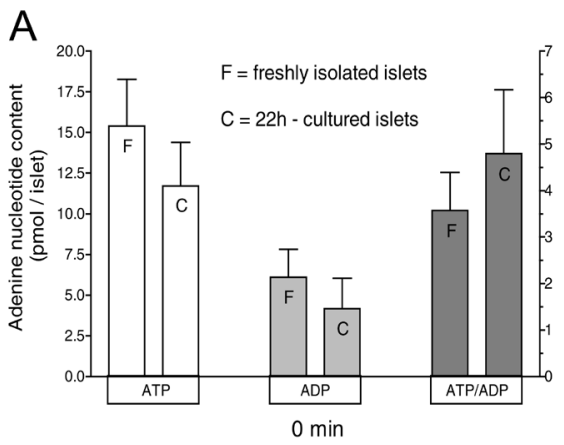

B

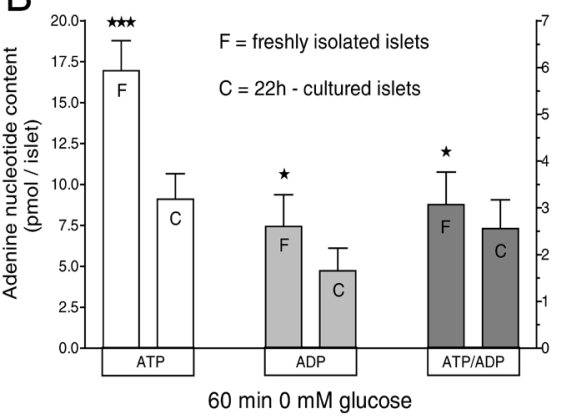

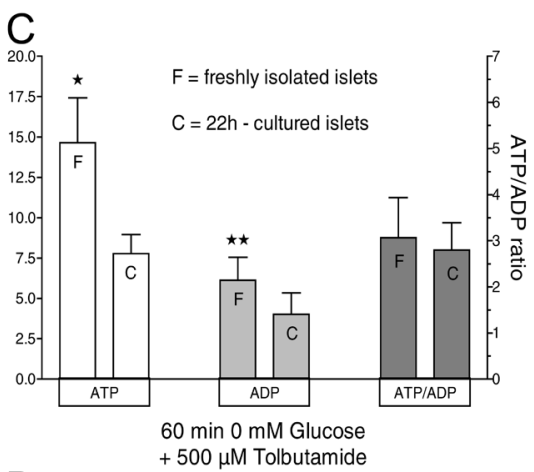

D

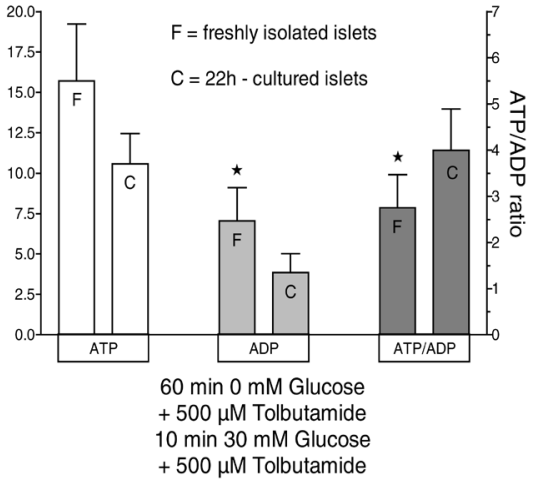

Figure 6

Adenine nucleotide contents in cultured islets as compared with freshly isolated islets. (A-C) The contents of ATP and ADP of 22-h-cultured islets and freshly isolated islets were determined after static incubation in KR medium without glucose. The duration was $0 \mathrm{~min}$ (A), $60 \mathrm{~min}$ (B) or $60 \mathrm{~min}$ in the additional presence of $500 \mu \mathrm{M}$ tolbutamide (C). (D) The fourth condition was $60 \mathrm{~min}$ followed by $30 \mathrm{mM}$ glucose for $10 \mathrm{~min}$, all in the additional presence of $500 \mu \mathrm{M}$ tolbutamide. Values are means \pm S.E.M. of six experiments each. $* P<0.05$, $\star \star P<0.01, * \star \star P P<0.001$, cultured vs fresh islets under the same condition, paired two-sided $t$-test. prestimulatory concentration was set to $5 \mathrm{mM}$ and the effects of $500 \mu \mathrm{M}$ tolbutamide and of $40 \mathrm{mM} \mathrm{KCl}$ were compared (Fig. 7). With fresh islets tolbutamide and $\mathrm{KCl}$ both generated a secretion pattern with a predominant first phase and a plateau phase thereafter. Culturing did not appreciably affect the response to tolbutamide and moderately increased the plateau phase in the response to $\mathrm{KCl}$ (Fig. 7A and B). To test whether the prestimulatory glucose concentration of $5 \mathrm{mM}$ was responsible for this result, the response to $30 \mathrm{mM}$ glucose was tested as well.
Here, a marked difference existed. After a comparable onset, the secretion of cultured islets decreased sharply and reached a nadir at 20 min, whereas the secretion of fresh islets only slowly decreased after a broad peak and resembled a square wave pattern (Fig. 7C). Both phases of secretion were significantly smaller in the cultured islets than in the fresh islets. This difference between cultured and fresh islets was also seen when the glucose concentration during culture was $10 \mathrm{mM}$ (Fig. 7D).
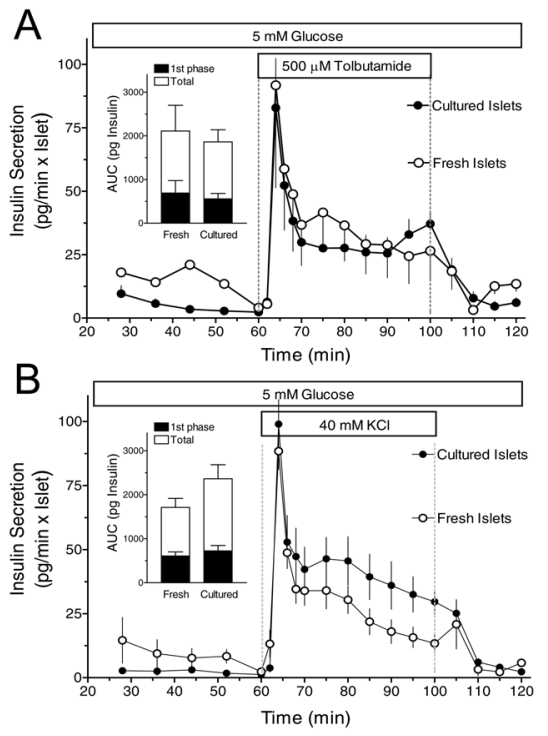

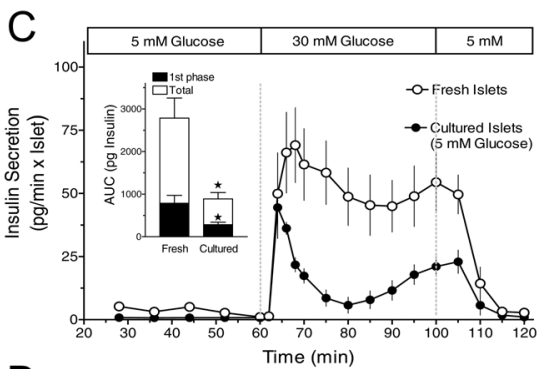

D

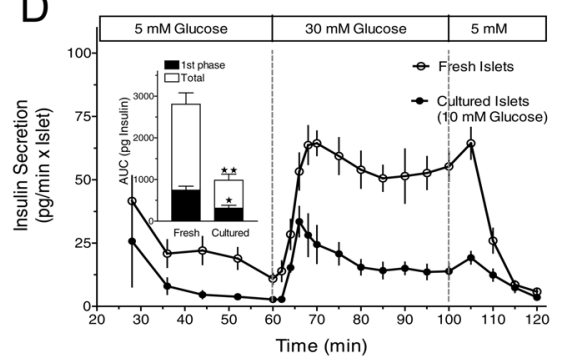

Figure 7

Kinetics of depolarization-induced insulin secretion of cultured and fresh islets. (A-C) 22-h-cultured islets (closed circles) or freshly isolated islets (open circles) were perifused with Krebs-Ringer medium containing $5 \mathrm{mM}$ glucose for $60 \mathrm{~min}$, then either $500 \mu \mathrm{M}$ tolbutamide (A) or $40 \mathrm{mM} \mathrm{KCl}(\mathrm{B})$ or $30 \mathrm{mM}$ glucose (C) was present for $40 \mathrm{~min}$ and was washed out thereafter. Note the similar secretion pattern of cultured and fresh islets in response to tolbutamide and $\mathrm{KCl}$ and the large difference in response to glucose. (D) This difference between cultured and fresh islets was also seen when the culture medium contained $10 \mathrm{mM}$ glucose. Values are means \pm S.E.M. of 4-5 experiments each. The inset shows the integrated insulin secretion from 60 to $75 \mathrm{~min}$ (1st phase) and from $60 \mathrm{~min}$ to washout (total). $* P<0.05$, $\star \star P<0.01$, cultured vs fresh islets under the same condition, unpaired two-sided $t$-test. https://ec.bioscientifica.com https://doi.org/10.1530/EC-20-0289 (c) 2020 The authors Published by Bioscientifica Ltd
This work is licensed under a Creative Commons Attribution-NonCommercial-NoDerivatives 4.0 International License ifica com at 04/26/2023 04:26:16 AM 


\section{Major but not exclusive role of FCS in shaping the predominant first phase kinetics of cultured islets}

The contribution of the two main components of the cell culture medium, RPMI and FCS, to shape the kinetics of secretion was assessed by replacing RPMI with KR-medium and $10 \%(\mathrm{v} / \mathrm{v})$ FCS with $0.4 \%(\mathrm{w} / \mathrm{v})$ BSA during the culture period. The glucose concentration was always $5 \mathrm{mM}$. Even though the total mass of released insulin differed considerably, the rapid onset of the first phase was visible under all conditions (Fig. 8). Islets cultured in RPMI with BSA showed the same pattern of secretion in response to 30 $\mathrm{mM}$ glucose as the islets which had been cultured in RPMI with FCS (Fig. 8A). However, the second phase secretion plateau was significantly lower (Fig. 8C). Islets cultured in KR-medium with FCS produced a comparable secretion pattern (Fig. 8B). The first phase and total secretion were not significantly different from those after culture in RPMI with FCS, but differed significantly from those after culture in KR with BSA (Fig. 8C). Such islets responded to $30 \mathrm{mM}$ glucose only with a modest increase for the first $15 \mathrm{~min}$ and a return to the very low prestimulatory levels thereafter. The different functional responses were not reflected by the appearance of the islets, which was essentially not different from islets after culture in RPMI plus FCS (Fig. 8D). Likewise, the total insulin content per islet was not significantly affected by the different culture conditions (Fig. 8E).

\section{Discussion}

The observations in this study suggest that the kinetics of insulin secretion which is regarded to be typical for mouse islets can be regularly observed after a culture phase, but much less frequently when freshly isolated islets are used. Cultured mouse islets nearly invariably responded to a square wave glucose stimulus with a prominent first phase secretion followed by a moderately elevated plateau. Depending on the prestimulatory conditions, the secretory response of fresh islets ranged from a moderate first phase followed by an ascending second phase to a virtual square wave response. In particular, the experimental condition reported to abolish the metabolic amplification of glucose, but not of KIC in fresh islets (14, 16) was unable to do so in cultured islets.

A cell culture period is widely considered to be essential for the work with isolated islets, since it is presumed to permit the recovery from the stress of collagenase isolation (17). It is also unavoidable if beta cells or islets are to be transfected. The more flexible experimental planning by the ready availability of cultured islets is
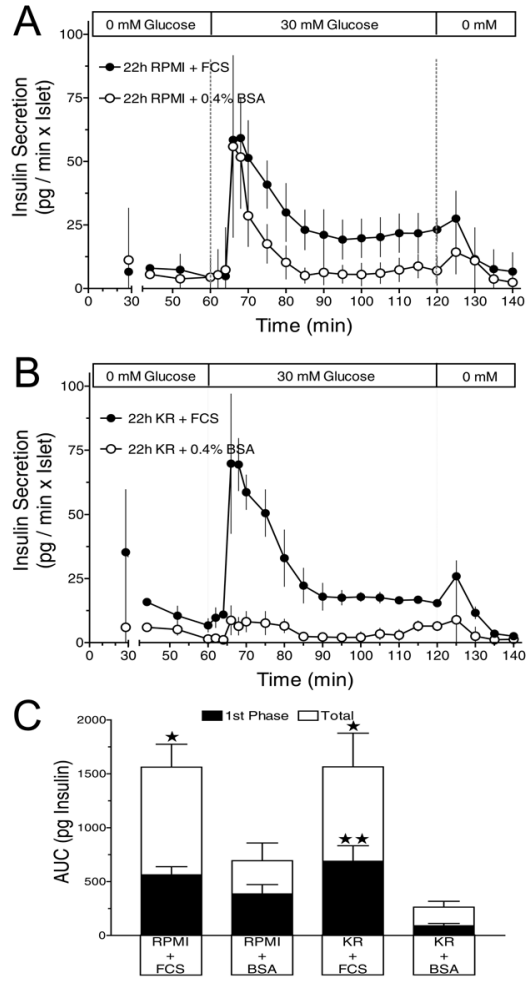

$\mathrm{D}$

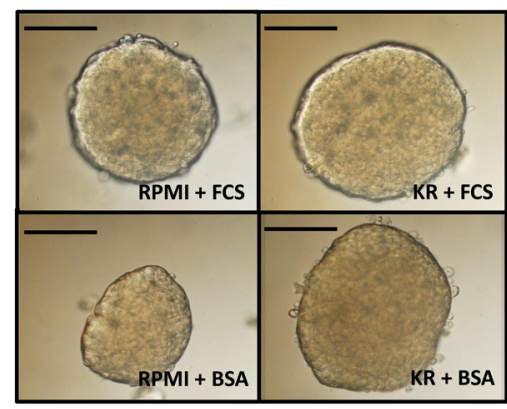

E

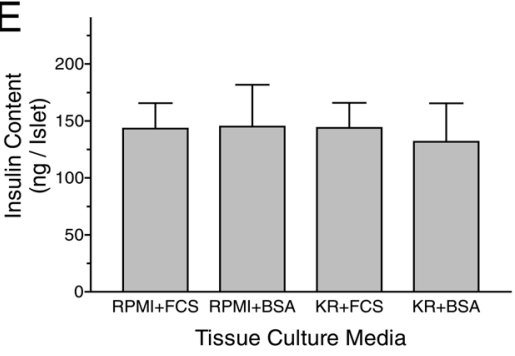

\section{Figure 8}

Effect of the composition of the cell culture medium on the kinetics of insulin secretion. (A) Islets cultured for $22 \mathrm{~h}$ either in RPMI + 10\% FCS (closed circles) or RPMI + 0.4\% BSA (open circles) were perifused with Krebs-Ringer (KR) medium containing $0 \mathrm{mM}$ glucose for $60 \mathrm{~min}$, then $30 \mathrm{mM}$ glucose was present for $60 \mathrm{~min}$ and was washed out thereafter. (B) The same protocol was used with islets cultured for $22 \mathrm{~h}$ either in $\mathrm{KR}+10 \%$ FCS (closed circles) or KR $+0.4 \%$ BSA (open circles). (C) The amount of insulin released during the entire duration of glucose stimulation in (A) and $(B)$ is shown by the white bars superimposed on the black bars, which show the one during the initial $15 \mathrm{~min} .{ }^{*} P<0.05, * * P<0.01$, when compared with the corresponding condition of BSA-cultured islets. Values are means \pm S.E.M. of five experiments each. (D) The different functional responses after culture were not reflected the microscopic appearance of the islets. DIC contrast mode, the bar length is 100 $\mu \mathrm{m}$. (E) The different culture conditions and secretion kinetics were not reflected by the insulin content of the islets. Values are means \pm S.E.M. of five experiments each. https://ec.bioscientifica.com https://doi.org/10.1530/EC-20-0289 (c) 2020 The authors Published by Bioscientifica Ltd

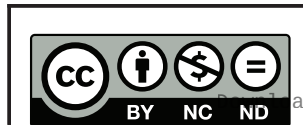

This work is licensed under a Creative Commons Attribution-NonCommercial-NoDerivatives 4.0 elnternationad dicense ifica. com at 04/26/2023 04:26:16AM 
an additional benefit. Currently, the wide availability of human islets (22) and the introduction of reconstituted islet spheroids (23) hold the promise to obtain more relevant information on human type 2 diabetes, but all these islets have spent considerable time under cell culture condition. The question is whether islet culture restores stimulus secretion coupling to its original state or leaves an imprint which may or may not correspond to the in vivo conditions.

It appears logical that islet culture diminishes the variability of the experimental observations seen with fresh islets, which reflects the different collagenase activities, the different methods of collagenase digestion (conventional method according to (24) vs duct injection according to (25)) and the different methods of islet collection (e.g. hand-picking vs density gradient collection, see (26)). Our experience shows that even minor changes in the collagenase isolation procedure can have detrimental consequences on the functional integrity of the freshly isolated islets. However, what precisely makes up the stress of isolation, which physiological functions of the islet are distorted by it and how culturing reverses these changes has not been well defined: Actually, much of the early ground-breaking work on the stimulus secretion coupling in beta cells was done with fresh islets (27).

The use of RPMI medium with the addition of $10 \%$ FCS was established early on as standard procedure for islet culture $(28,29,30)$. Later, it was described that glucose at a moderate stimulatory concentration (11 mM) keeps the apoptosis rate during culture at a minimum (31), in line with the earlier observation that the absence of serum during culture could be partially compensated for by elevated glucose levels (29). Under our conditions necrotic cells were rare both in fresh and in 1-day-cultured islets. Apoptosis at an early stage was only visible in the outermost cell layer of fresh islets, which may mostly consist of exocrine cells. After the culture phase the labeling by annexin $\mathrm{V}$ was still visible but more scattered, suggesting some of these cells had disintegrated. The incubation of fresh islets for 60 min without exogenous nutrient did not increase the annexin $\mathrm{V}$ labeling and necrotic cells remained exceedingly rare. In our view fresh collagenase-isolated islets, if gently and quickly isolated (which is easier to achieve with mouse pancreas than with porcine or human pancreas) are structurally intact, establish steady state conditions within $1 \mathrm{~h}$ of perifusion and can give meaningful information on stimulus secretion coupling.

There are few publications addressing the secretion kinetics of cultured islets as compared with that of freshly isolated islets. Zawalich et al. found that a very short term culture $(3 \mathrm{~h})$ transformed the elevated plateau in response to $11 \mathrm{mM}$ glucose into an ascending second phase (32). Ravier et al. described a strongly decreased steady state secretion, preceded by a predominant first phase, when mouse islets had been cultured overnight in $5 \mathrm{mM}$ glucose (33). This change parallels our observation on how culturing transformed the secretion elicited by elevating glucose from 5 to $30 \mathrm{mM}$ (Fig. 7C). The predominant first phase was also visible after overnight culture in $10 \mathrm{mM}$ glucose even though the secretion level was markedly increased vs $5 \mathrm{mM}$ (33).

In the intact organism a brisk first phase is particularly important for the glucose homeostasis (4, $5)$, so the more prominent first phase of cultured islets in response to glucose (Fig. 1A and B) may be viewed as a gain of functional competence. However, in response to KIC the freshly isolated islets showed the faster onset of secretion with a comparable magnitude of the first phase (Fig. 1C and D). This suggests that glucose-specific factors in stimulus-secretion coupling rather than unspecific structural defects were affected by the culture period. The close similarity between the kinetics of fresh and cultured islets when responding to purely depolarizing stimuli supports this view. Of note, microdissected islets showed a similar change of secretion kinetics as collagenase-isolated islets after culture (Fig. 2E), so the repair of collagenaseinduced structural defects is unlikely to underlie the change in secretion kinetics.

Recently, the loss of the metabolic amplification by prior depolarization in the absence of exogenous nutrients was traced back to the time-dependent depletion of critical endogenous metabolites in freshly isolated islets $(16,34)$. Conversely, the preserved metabolic amplification in cultured islets would then be due to the higher abundance of endogenous metabolites or their slower consumption. In view of the lower prestimulatory NAD(P)H/FAD-ratios in the cultured islets the latter assumption may be correct. Here it has to be kept in mind that the level of reducing equivalents in the mitochondrial matrix, of which the $\mathrm{NAD}(\mathrm{P}) \mathrm{H} / \mathrm{FAD}$ ratio is a semi-quantitative measure, is in flow equilibrium between generation in the Krebs cycle and consumption in the respiratory chain. Since we found cultured islets to consume oxygen at a lower rate than fresh islets (M Morsi and I Rustenbeck, unpublished observations), it may be the slower generation which is responsible for the lower level of reducing equivalents.

Both, the NAD $(\mathrm{P}) \mathrm{H}$ - and the FAD-fluorescence levels were lower after culture. The contribution of NADPH to the $\mathrm{NAD}(\mathrm{P}) \mathrm{H}$ fluorescence signal is only of minor 
importance, since in beta cells glucose increases NADH as well as NADPH, probably coupled by a diminished NADPH consumption via the NNT (nicotinamide nucleotide transhydrogenase) running in the reverse direction (35). Interestingly, FAD was proportionally less decreased than $\mathrm{NAD}(\mathrm{P}) \mathrm{H}$, resulting in the lower NAD(P)H/FAD ratio values (Fig. 5). Mitochondrial sites of FAD consumption are the succinate dehydrogenase reaction and the glycerol phosphate shuttle, where FADH2 is generated. Additionally, the dihydrolipoyl dehydrogenase within the pyruvate dehydrogenase complex reduces protein-bound FAD to FADH2 to ultimately generate $\mathrm{NADH}$ (for overviews on mitochondrial metabolism in beta cells see $(36,37,38))$.

A decreased activity of these enzymes, in particular of the pyruvate dehydrogenase offers a straightforward explanation for the decreased $\mathrm{NAD}(\mathrm{P}) \mathrm{H} / \mathrm{FAD}$ ratio in cultured islets. It is conceivable that because of the resulting changes in mitochondrial metabolite flux the consumption of oxaloacetate is slower than in fresh islets, where oxaloacetate is likely the first Krebs cycle metabolite to become critically low during prolonged phases of depolarization in the absence of nutrients $(15,16,34)$.

The adenine nucleotide levels were not significantly different in cultured and fresh islets at the beginning of the experiments. In view of the higher oxygen consumption of fresh islets mentioned above this may seem to indicate less well coupled mitochondria. However, the islet ATP content is strongly influenced by the ATP content in the insulin granules (39), which may obscure the relevant features. What appears to be relevant is different development of the adenine nucleotide contents during nutrient deprivation. Specifically, the lower content of adenine nucleotides and the lower ATP/ADP ratio in cultured islets after 60 min suggests a slower consumption of endogenous metabolites. The significantly higher ATP/ADP ratio in cultured islets after subsequent exposure to $30 \mathrm{mM}$ glucose (Fig. 6D) together with a larger increase of the NAD(P)H/FAD ratio (Fig. 5D) suggests that under this condition glucose was better able to accelerate the oxidative phosphorylation, probably via the increased generation of reducing equivalents.

Another feature related to the different activity of oxidative phosphorylation is the marked transient decrease of $\left[\mathrm{Ca}^{2+}\right]_{\mathrm{i}}$ in cultured islets at the beginning of the glucose stimulation, specifically when $\left[\mathrm{Ca}^{2+}\right]_{\mathrm{i}}$ was elevated by prior exposure to tolbutamide (compare Fig. $2 \mathrm{~A}$ and $\mathrm{B}$ ). It is known that the transient dip is caused by the activation of SERCA pumps $(40,41)$, which respond to the ATP availability. The initial decrease in $\left[\mathrm{Ca}^{2+}\right]_{\mathrm{i}}$ was found to be more pronounced after 1-day culture in $5 \mathrm{mM}$ than after culture in $10 \mathrm{mM}$ glucose (42). After culture in $10 \mathrm{mM}$ glucose virtually no decrease in $\left[\mathrm{Ca}^{2+}\right]_{\mathrm{i}}$ occurred, similar to the fresh islets in the present investigation. Thus the initial decrease is not an obligatory criterion for a functioning intracellular $\mathrm{Ca}^{2+}$ transport.

The generally higher prestimulatory $\left[\mathrm{Ca}^{2+}\right]_{\mathrm{i}}$ levels in fresh islets were probably not caused by a lack of ATP required for $\mathrm{Ca}^{2+}$ sequestration and extrusion pumps, but may result from the reversible dissociation of gap junction channels (connexons) between beta cells whereby $\mathrm{Ca}^{2+}$ permeable hemichannels are formed $(43,44)$. While the initial kinetics of $\left[\mathrm{Ca}^{2+}\right]_{i}$ paralleled the increase of glucose-stimulated insulin secretion, the further course of secretion was not reflected by the changes in $\left[\mathrm{Ca}^{2+}\right]_{\mathrm{i}}$ levels. This was as true for the cultured islets as for the fresh islets (Fig. 2A and C). So in both fresh and cultured islets the generation of amplifying signals appears to shape the secretion pattern.

Considering the consequences of exchanging the components of the culture medium (RPMI against KR and FCS against BSA) for the kinetics of glucose-induced secretion, it is obvious that the predominance of the first phase in cultured islets was a very robust feature (Fig. 8). So it is unlikely to result from specific nutrients contained in RPMI but not KR. FCS supported the overall secretory capacity much better than BSA, but its absence during culture did not abolish the predominant first phase. In this context we found the observation intriguing that mice in vivo were shown to have a biphasic response with an ascending second phase, which was no longer visible after culture of these islets (45). The authors hypothesized that the difference was due to the loss of an in vivo input like innervation or incretin hormones. The fact that the secretion pattern of the perfused mouse pancreas $(46,47)$ is similar to that of cultured islets also points in this direction.

In summary, the secretion kinetics of fresh mouse islets is more responsive to variations of nutrient stimulation whereas cultured islets respond with uniform kinetics, the pattern of which resembles the one elicited by purely depolarizing stimuli. Even though the isolation procedure may affect islet function, it is not damaging to the islet structure, if appropriately performed. Conversely, the altered kinetics after culture does not simply represent a reset to the original working conditions. It remains to be clarified whether it is due to a lack of signals present in vivo or whether general conditions of the culture phase leave an imprint on the nutrient metabolism of the beta cell.

This work is licensed under a Creative Commons Attribution-NonCommercial-NoDerivatives 4.0 elnternational License.ifica, com at 04/26/2023 04:26:16 AM 


\section{Supplementary materials}

This is linked to the online version of the paper at https://doi.org/10.1530/ EC-20-0289.

\section{Declaration of interest}

The authors declare that there is no conflict of interest that could be perceived as prejudicing the impartiality of the research reported.

\section{Funding}

This work was supported by grants from the Deutsche Forschungsgemeinschaft (DFG Ru 368/5-4) and the DDG - Deutsche Diabetes Gesellschaft. T S was supported by the Quanomet Project of the Lower Saxony Ministry for Science and Culture.

\section{Author contribution statement}

$\mathrm{M} \mathrm{M}$ isolated the pancreatic islets and performed microfluorometric and insulin secretion experiments. T S and E F isolated the pancreatic islets and measured the cytosolic $\mathrm{Ca}^{2+}$ concentration. $\mathrm{D}$ B performed imaging. $\mathrm{I} \mathrm{R}$ and $\mathrm{U} \mathrm{P}$ conceived experiments and wrote the manuscript. All authors discussed results.

\section{Acknowledgements}

Expert technical assistance by Angela Hahlbohm, Verena Lier-Glaubitz and Johannes Sievers (Institute of Pharmacology, Toxicology and Clinical Pharmacy, Technische Universität Braunschweig) is gratefully acknowledged.

\section{References}

1 Nesher R \& Cerasi E. Biphasic insulin release as the expression of combined inhibitory and potentiating effects of glucose. Endocrinology 1987121 1017-1024. (https://doi.org/10.1210/endo121-3-1017)

2 Nesher R \& Cerasi E. Modeling phasic insulin release: immediate and time-dependent effects of glucose. Diabetes 200251 (Supplement 1) S53-S59. (https://doi.org/10.2337/diabetes.51.2007.s53)

3 Cerasi E, Luft R \& Efendic S. Decreased sensitivity of the pancreatic beta cells to glucose in prediabetic and diabetic subjects. A glucose dose-response study. Diabetes 197221 224-234. (https://doi. org/10.2337/diab.21.4.224)

4 Gerich JE. Is reduced first-phase insulin release the earliest detectable abnormality in individuals destined to develop type 2 diabetes? Diabetes 200251 (Supplement 1) S117-S121. (https://doi. org/10.2337/diabetes.51.2007.s117)

5 Del Prato S. Loss of early insulin secretion leads to postprandial hyperglycaemia. Diabetologia 200346 (Supplement 1) M2-M8. (https://doi.org/10.1007/s00125-002-0930-6)

6 Rorsman P \& Renström E. Insulin granule dynamics in pancreatic beta cells. Diabetologia 200346 1029-1045. (https://doi.org/10.1007/ s00125-003-1153-1)

7 Straub SG \& Sharp GW. Hypothesis: one rate-limiting step controls the magnitude of both phases of glucose-stimulated insulin secretion. American Journal of Physiology: Cell Physiology 2004287 C565-C571. (https://doi.org/10.1152/ajpcell.00079.2004)

8 Henquin JC. Triggering and amplifying pathways of regulation of insulin secretion by glucose. Diabetes 200049 1751-1760. (https:// doi.org/10.2337/diabetes.49.11.1751)
9 Daniel S, Noda M, Straub SG \& Sharp GW. Identification of the docked granule pool responsible for the first phase of glucosestimulated insulin secretion. Diabetes 199948 1686-1690. (https:// doi.org/10.2337/diabetes.48.9.1686)

10 Henquin JC, Nenquin M, Stiernet P \& Ahren B. In vivo and in vitro glucose-induced biphasic insulin secretion in the mouse: pattern and role of cytoplasmic $\mathrm{Ca}^{2+}$ and amplification signals in beta-cells. Diabetes 200655 441-451. (https://doi.org/10.2337/ diabetes.55.02.06.db05-1051)

11 Hatlapatka K, Willenborg M \& Rustenbeck I. Plasma membrane depolarization as a determinant of the first phase of insulin secretion. American Journal of Physiology: Endocrinology and Metabolism 2009297 E315-E322. (https://doi.org/10.1152/ ajpendo.90981.2008)

12 Panten U, Schwanstecher M, Wallasch A \& Lenzen S. Glucose both inhibits and stimulates insulin secretion from isolated pancreatic islets exposed to maximally effective concentrations of sulfonylureas. Naunyn-Schmiedeberg's Archives of Pharmacology 1988338 459-462. (https://doi.org/10.1007/BF00172128)

13 Gembal M, Gilon P \& Henquin JC. Evidence that glucose can control insulin release independently from its action on ATP-sensitive $\mathrm{K}^{+}$ channels in mouse B cells. Journal of Clinical Investigation 199289 1288-1295. (https://doi.org/10.1172/JCI115714)

14 Urban KA \& Panten U. Selective loss of glucose-induced amplification of insulin secretion in mouse pancreatic islets pretreated with sulfonylurea in the absence of fuels. Diabetologia 200548 2563-2566. (https://doi.org/10.1007/s00125-005-0030-5)

15 Panten U, Willenborg M, Schumacher K, Hamada A, Ghaly H \& Rustenbeck I. Acute metabolic amplification of insulin secretion in mouse islets is mediated by mitochondrial export of metabolites, but not by mitochondrial energy generation. Metabolism: Clinical and Experimental 201362 1375-1386. (https://doi.org/10.1016/j. metabol.2013.05.006)

16 Schulze T, Morsi M, Reckers K, Brüning D, Seemann N, Panten U $\&$ Rustenbeck I. Metabolic amplification of insulin secretion is differentially desensitized by depolarization in the absence of exogenous fuels. Metabolism: Clinical and Experimental 201767 1-13. (https://doi.org/10.1016/j.metabol.2016.10.008)

17 Carter JD, Dula SB, Corbin KL, Wu R \& Nunemaker CS. A practical guide to rodent islet isolation and assessment. Biological Procedures Online 200911 3-31. (https://doi.org/10.1007/s12575-009-9021-0)

18 Willenborg M, Schumacher K \& Rustenbeck I. Determination of betacell function: insulin secretion of isolated islets. Methods in Molecular Biology 2012933 189-201. (https://doi.org/10.1007/978-1-62703068-7_12)

19 Martin SJ, Reutelingsperger CP, McGahon AJ, Rader JA, van Schie RC, LaFace DM \& Green DR. Early redistribution of plasma membrane phosphatidylserine is a general feature of apoptosis regardless of the initiating stimulus: inhibition by overexpression of Bcl-2 and Abl. Journal of Experimental Medicine 1995182 1545-1556. (https://doi. org/10.1084/jem.182.5.1545)

20 Panten U \& Ishida H. Fluorescence of oxidized flavoproteins from perifused isolated pancreatic islets. Diabetologia 197511 569-573. (https://doi.org/10.1007/BF01222108)

21 Rocheleau JV, Head WS \& Piston DW. Quantitative NAD(P)H/ flavoprotein autofluorescence imaging reveals metabolic mechanisms of pancreatic islet pyruvate response. Journal of Biological Chemistry 2004279 31780-31787. (https://doi.org/10.1074/jbc.M314005200)

22 Henquin JC. The challenge of correctly reporting hormones content and secretion in isolated human islets. Molecular Metabolism 201930 230-239. (https://doi.org/10.1016/j.molmet.2019.10.003)

23 Kim HJ, Alam Z, Hwang JW, Hwang YH, Kim MJ, Yoon S, Byun Y \& Lee DY. Optimal formation of genetically modified and functional pancreatic islet spheroids by using hanging-drop strategy. Transplantation Proceedings 201345 605-610. (https://doi. org/10.1016/j.transproceed.2012.11.014) 
24 Moskalewski S. Isolation and culture of the islets of Langerhans of the guinea pig. General and Comparative Endocrinology 19655 342-353. (https://doi.org/10.1016/0016-6480(65)90059-6)

25 Gotoh M, Maki T, Satomi S, Porter J, Bonner-Weir S, O'Hara CJ $\&$ Monaco AP. Reproducible high yield of rat islets by stationary in vitro digestion following pancreatic ductal or portal venous collagenase injection. Transplantation 198743 725-730. (https://doi. org/10.1097/00007890-198705000-00024)

26 Brunstedt J. Rapid isolation of functionally intact pancreatic islets from mice and rats by Percoll gradient centrifugation. Diabete and Metabolisme 19806 87-89.

27 Hedeskov CJ. Mechanism of glucose-induced insulin secretion. Physiological Reviews 198060 442-509. (https://doi.org/10.1152/ physrev.1980.60.2.442)

28 Buitrago A, Gylfe E, Hellman B, Idahl LA \& Johansson M. Function of microdissected pancreatic islets cultured in a chemically defined medium. I. Insulin content and release. Diabetologia 197511 535-540. (https://doi.org/10.1007/BF01222103)

29 Andersson A. Isolated mouse pancreatic islets in culture: effects of serum and different culture media on the insulin production of the islets. Diabetologia 197814 397-404. (https://doi.org/10.1007/ BF01228134)

30 Andersson A, Borg H, Hallberg A, Hellerström C, Sandler S \& Schnell A. Long-term effects of cyclosporin A on cultured mouse pancreatic islets. Diabetologia 198427 (Supplement) 66-69. (https:// doi.org/10.1007/BF00275649)

31 Efanova IB, Zaitsev SV, Zhivotovsky B, Köhler M, Efendić S, Orrenius $S$ \& Berggren PO. Glucose and tolbutamide induce apoptosis in pancreatic beta-cells. A process dependent on intracellular $\mathrm{Ca}^{2+}$ concentration. Journal of Biological Chemistry 1998 273 33501-33507. (https://doi.org/10.1074/jbc.273.50.33501)

32 Zawalich WS, Yamazaki H \& Zawalich KC. Biphasic insulin secretion from freshly isolated or cultured, perifused rodent islets: comparative studies with rats and mice. Metabolism: Clinical and Experimental 2008 57 30-39. (https://doi.org/10.1016/j.metabol.2007.07.020)

33 Ravier MA, Nenquin M, Miki T, Seino S \& Henquin JC. Glucose controls cytosolic $\mathrm{Ca}^{2+}$ and insulin secretion in mouse islets lacking adenosine triphosphate-sensitive $\mathrm{K}^{+}$channels owing to a knockout of the pore-forming subunit Kir6.2. Endocrinology 2009150 33-45. (https://doi.org/10.1210/en.2008-0617)

34 Panten U, Früh E, Reckers K \& Rustenbeck I. Acute metabolic amplification of insulin secretion in mouse islets: role of cytosolic acetyl-CoA. Metabolism: Clinical and Experimental $2016 \mathbf{6 5}$ 1225-1229. (https://doi.org/10.1016/j.metabol.2016.05.001)

35 Santos LRB, Muller C, de Souza AH, Takahashi HK, Spégel P, Sweet IR, Chae H, Mulder H \& Jonas JC. NNT reverse mode of operation mediates glucose control of mitochondrial NADPH and glutathione redox state in mouse pancreatic $\beta$-cells. Molecular Metabolism 20176 535-547. (https://doi.org/10.1016/j.molmet.2017.04.004)

36 Jitrapakdee S, Wutthisathapornchai A, Wallace JC \& MacDonald MJ. Regulation of insulin secretion: role of mitochondrial signalling. Diabetologia 201053 1019-1032. (https://doi.org/10.1007/s00125010-1685-0)

37 Nicholls DG. The pancreatic $\beta$-cell: a bioenergetic perspective. Physiological Reviews 201696 1385-1447. (https://doi.org/10.1152/ physrev.00009.2016)

38 Fex M, Nicholas LM, Vishnu N, Medina A, Sharoyko VV, Nicholls DG, Spégel P \& Mulder H. The pathogenetic role of $\beta$-cell mitochondria in type 2 diabetes. Journal of Endocrinology 2018236 R145-R159. (https://doi.org/10.1530/JOE-17-0367)

39 Detimary P, Jonas JC \& Henquin JC. Stable and diffusible pools of nucleotides in pancreatic islet cells. Endocrinology 1996137 4671-4676. (https://doi.org/10.1210/endo.137.11.8895332)

40 Chow RH, Lund PE, Löser S, Panten U \& Gylfe E. Coincidence of early glucose-induced depolarization with lowering of cytoplasmic $\mathrm{Ca}^{2+}$ in mouse pancreatic beta-cells. Journal of Physiology 1995485 607-617. (https://doi.org/10.1113/jphysiol.1995.sp020756)

41 Hellman B \& Grapengiesser E. Glucose-induced inhibition of insulin secretion. Acta Physiologica 2014210 479-488. (https://doi. org/10.1111/apha.12217)

42 Gilon P, Jonas JC \& Henquin JC. Culture duration and conditions affect the oscillations of cytoplasmic calcium concentration induced by glucose in mouse pancreatic islets. Diabetologia 199437 1007-1014. (https://doi.org/10.1007/BF00400464)

43 Ravier MA, Güldenagel M, Charollais A, Gjinovci A, Caille D, Söhl G, Wollheim CB, Willecke K, Henquin JC \& Meda P. Loss of connexin 36 channels alters beta-cell coupling, islet synchronization of glucose-induced $\mathrm{Ca}^{2+}$ and insulin oscillations, and basal insulin release. Diabetes 200554 1798-1807. (https://doi.org/10.2337/ diabetes.54.6.1798)

44 Seemann N, Welling A \& Rustenbeck I. The inhibitor of connexin Cx36 channels, mefloquine, inhibits voltage-dependent $\mathrm{Ca}^{2+}$ channels and insulin secretion. Molecular and Cellular Endocrinology 2018472 97-106. (https://doi.org/10.1016/j.mce.2017.11.024)

45 Nunemaker CS, Wasserman DH, McGuinness OP, Sweet IR, Teague JC \& Satin LS. Insulin secretion in the conscious mouse is biphasic and pulsatile. American Journal of Physiology: Endocrinology and Metabolism 2006290 E523-E529. (https://doi.org/10.1152/ajpendo.00392.2005)

46 Lenzen S. Insulin secretion by isolated perfused rat and mouse pancreas. American Journal of Physiology 1979236 E391-E400. (https://doi.org/10.1152/ajpendo.1979.236.4.E391)

47 Berglund O. Different dynamics of insulin secretion in the perfused pancreas of mouse and rat. Acta Endocrinologica 198093 54-60. (https://doi.org/10.1530/acta.0.0930054)

Received in final form 10 July 2020

Accepted 19 July 2020

Accepted Manuscript published online 20 July 2020 https://ec.bioscientifica.com https://doi.org/10.1530/EC-20-0289
(C) 2020 The authors Published by Bioscientifica Ltd

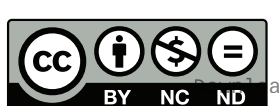

This work is licensed under a Creative Commons Attribution-NonCommercial-NoDerivatives 4.0 elnternationab ficense.ifica com at 04/26/2023 04:26:16AM 